\title{
The Effect of Er:YAG Laser Irradiation Combined With Fluoride Application on the Resistance of Primary and Permanent Dental Enamel to Erosion
}

\author{
Fatemeh Molla Asadollah', Seyed Masoud Mojahedi ${ }^{2}$, Hanie Nojedehian ${ }^{3}$, Mohammad Asnaasharii, $^{4,5}$ Negin \\ Asnaashari* ${ }^{4 *}$

\begin{abstract}
'Department of Pediatric Dentistry, School of Dentistry, Shahid Beheshti University of Medical Sciences, Tehran, Iran ${ }^{3}$ Department of Dental Biomaterials, School of Dentistry, Shahid Beheshti University of Medical Sciences ${ }^{4}$ Laser Application in Medical Sciences Research Center, Shahid Beheshti University of Medical Sciences, Tehran, Iran ${ }^{5}$ Department of Endodontics, School of Dentistry, Shahid Beheshti University of Medical Sciences, Tehran, Iran
\end{abstract} \\ ${ }^{2}$ Department of Laser, School of Dentistry, Shahid Beheshti University of Medical Sciences, Tehran, Iran
}

\author{
*Correspondence to \\ Negin Asnaashari \\ Email: \\ negin_asna12@yahoo.com
}

Published online October 1 2019

\begin{abstract}
Introduction: Erosion is an important cause of tooth mineral loss. The combined use of lasers and fluoride has been introduced as a novel modality for the prevention of enamel demineralization. This study aimed to assess the effect of Er:YAG laser combined with fluoride application on primary and permanent enamel resistance to erosion.

Methods: Eighty enamel specimens of permanent $(n=40)$ and primary $(n=40)$ molars were prepared and randomly assigned to 4 groups: C-control (no pretreatment), F-acidulated phosphate fluoride (APF) gel, FL-APF gel application followed by Er:YAG laser irradiation, and LF-Er:YAG laser irradiation followed by the application of APF gel. The specimens were then submitted to $\mathrm{pH}$ cycling using Coca-Cola $(\mathrm{pH}=2.4)$. Enamel micro-hardness was measured using the Vickers microhardness tester before pretreatment and after the erosive process. The collected data were analyzed using the Kolmogorov-Smirnov test, two-way ANOVA and repeated measures ANOVA.

Results: The micro-hardness of both permanent and primary enamel specimens significantly decreased after the erosive process $(P<0.05)$. In the permanent enamel specimens, the greatest reduction in micro-hardness was noted in groups $C$ and $F$, while the least reduction was noted in group FL. However, these differences were not statistically significant $(P>0.05)$. In the primary enamel specimens, the greatest reduction in micro-hardness was noted in groups $C$ and LF, while the least reduction was noted in group $F$. These differences were not statistically significant $(P>0.05)$. Conclusion: Within the limitations of this study, Er:YAG laser irradiation combined with fluoride application could not prevent erosion in permanent and primary enamel during the erosive process. Keywords: Tooth Erosion; Er:YAG Laser; Fluoride; Dentition; Permanent; Tooth; Primary.
\end{abstract}

\section{Introduction}

The prevalence of dental erosive wear has increased in recent years due to the change in lifestyle and the increased use of acidic beverages. ${ }^{1,2}$ Erosive tooth wear is an important cause of tooth mineral loss in children and adolescents. ${ }^{3}$ Dental erosion refers to progressive and irreversible loss of tooth structure during a chemical process without the involvement of bacteria. ${ }^{4}$ Erosion is caused by intrinsic and extrinsic acids that dissolve the hydroxyapatite crystals of enamel and cause tooth hypersensitivity, change in tooth morphology, unaesthetic appearance, and pulp exposure in severe cases. External factors causing erosion include the use of acidic foods and carbonated beverages, fruit juices, citrus and to a lesser extent, occupational exposure to acidic environments. ${ }^{5}$ The most common intrinsic factors include chronic gastrointestinal diseases such as gastrointestinal reflux, anorexia and bulimia (due to frequent vomiting). ${ }^{5-7}$ Hydrochloric acid in gastric juice has a low $\mathrm{pH}$ (1.5 to 3 ) and can cause severe erosion if it is refluxed into the mouth. ${ }^{8}$

Enamel demineralization is the initial phase of the erosive process, which is characterized by the initial softening of enamel and increased surface roughness. ${ }^{9}$

Please cite this article as follows: Asadollah FM, Mojahedi SM, Nojedehian H, Asnaashari M, Asnaashari N. The effect of Er:YAG laser irradiation combined with fluoride application on the resistance of primary and permanent dental enamel to erosion. I Lasers Med Sci. 2019;10(4):290-296. doi:10.15171/jlms.2019.47. 
In the advanced stages of dental erosion, dentin is increasingly exposed and tooth hypersensitivity and change in tooth anatomy may occur. ${ }^{10}$

Considering the increased prevalence of dental erosion and its irreversibility, early detection and proper measures to prevent and control it are important. ${ }^{11,12}$ Erosive lesions repeatedly require preventive and restorative treatments. ${ }^{13}$ However, restorative treatments cannot prevent further progression of erosive/abrasive wear. ${ }^{14}$ Preventive strategies such as controlled diet and nutrition, stimulation of salivary flow, fluoride application, limiting the consumption of erosive drinks, using buffering agents and improving oral hygiene can decrease demineralization due to the acids of a nonbacterial origin. ${ }^{14,15}$ However, controlling all etiologic factors is difficult if not impossible because it requires patient cooperation. ${ }^{12}$ For this reason, other modalities such as fluoride therapy and laser therapy that do not require patient cooperation, were introduced to prevent or stop the process of erosion and subsequent tooth hypersensitivity. ${ }^{16}$

The application of fluoride-containing products such as $1.23 \%$ acidulated phosphate fluoride (APF) gel is reportedly effective in the prevention of erosion since it decreases the penetration depth of acids into the enamel., ${ }^{2,7}$ This protective act of fluoride is due to the formation of a superficial $\mathrm{CaF}_{2}$ layer that prevents the exposure of enamel to acids and its dissolution. ${ }^{18}$ However, some studies have shown that the efficacy of fluoride therapy in controlling dental erosion is limited. ${ }^{19,20}$ This highlights the need for novel modalities such as laser therapy for the prevention and control of dental erosion.

Some studies have shown that the application of Nd:YAG laser along with APF gel is effective in the prevention of erosion. ${ }^{21,22} \mathrm{CO}_{2}$ laser has been used for the prevention of erosion in many previous studies. ${ }^{3,9,12,23-27}$ Ramalho et $\mathrm{al}^{3,27}$ and Esteves-Oliveira et $\mathrm{a}^{28}$ showed that $\mathrm{CO}_{2}$ laser irradiation with $0.3 \mathrm{~J} / \mathrm{cm}^{2}$ energy density, $5 \mu \mathrm{s}$ pulse width, and $226 \mathrm{~Hz}$ frequency decreased enamel loss during the erosive process. However, these parameters are not available in clinical laser devices. ${ }^{29}$

Although some studies have reported the positive efficacy of Er:YAG laser irradiation in the prevention of tooth decay, ${ }^{30,31}$ information is limited on its efficacy in the prevention of erosive demineralization. Azevedo et $\mathrm{al}^{32}$ reported that Er:YAG laser irradiation combined with the application of APF gel effectively decreased bovine enamel dissolution during erosive processes. However, Scatolin et $\mathrm{al}^{33,34}$ indicated that Er:YAG laser irradiation alone could not slow down the progression of erosive lesions caused by citric acid.

Considering the fact that Er:YAG laser irradiation can reinforce the crystallinity of the enamel ${ }^{35}$ and enhance the deposition of $\mathrm{CaF}_{2}$ on the enamel surface, ${ }^{36}$ this study aimed to assess the effect of Er:YAG laser irradiation combined with fluoride application on primary and permanent enamel resistance to erosion.

\section{Materials and Methods}

This in vitro experimental study was conducted on the extracted primary molars and the permanent third molars. The inclusion criteria were sound human primary molar and permanent third molar teeth. The exclusion criteria were the presence of caries, cracks, wear and enamel hypoplasia.

The sample size was calculated to be 10 in each group (40 in total) according to a study by Esteves-Oliveira et $\mathrm{al}^{28}$ assuming the effect size of 0.6 , power of $80 \%$, and alpha $=0.05$ by using the one-way ANOVA feature of PASS software. Thus, 20 primary and 20 permanent teeth were included using convenience sampling. The teeth were then randomly divided into 4 groups and stored in $0.1 \%$ thymol solution until the experiment. The teeth were first cleaned of calculus, dental plaque and debris using a scaler and a non-fluoride prophylaxis paste with low-speed handpiece. The teeth were then sectioned into buccal and lingual halves using a low-speed saw (Isomet, Cuehler Ltd., USA). Eighty samples were prepared as such. The samples were embedded in transparent autopolymerizing acrylic resin (Acropars, Tehran, Iran) using a mold, with the enamel surfaces (buccal or lingual surface) facing upwards. The enamel surfaces were ground flat and polished using the following sequence of silicon carbide abrasive papers: 400, 600, 800, 1000, 1500, 2000 and 2500-grit.

Adhesive tapes measuring $3 \times 3 \mathrm{~mm}^{2}$ were placed on the samples and the rest of the surface was coated with 2 layers of nail varnish. After drying the varnish and removing the tapes, the samples were rinsed with deionized water. The enamel windows were created as such. The samples were then coded with a marker and a bur placed in a highspeed hand-piece, and stored in deionized water.

\section{Measurement of Baseline Surface Micro-hardness}

The baseline surface micro-hardness ( $\mathrm{SMH}$ ) was measured using a Vickers micro-hardness tester (V-test, Bareiss Prüfgerätebau $\mathrm{GmbH}$, Oberdischingen, Germany). According to a previous study, ${ }^{37} 100 \mathrm{~g}$ load was applied to three points on the surface of each sample (with the minimum distance of $120 \mu \mathrm{m}$ ) for 10 seconds, and the micro-hardness was measured at the three indentations. The mean of the three values was calculated and recorded as the micro-hardness of the respective sample.

\section{Grouping of the Samples and Their Pretreatment}

The enamel samples in each of the primary molar $(n=40)$ and permanent molar $(n=40)$ groups were divided into 4 groups $(\mathrm{n}=10)$ as follows:

- Group 1: Control group with no pretreatment (C)

- Group 2: APF gel application (F)

- Group 3: APF gel application followed by Er:YAG laser irradiation (FL)

- Group 4: Er:YAG laser irradiation followed by APF gel application (LF) 
In groups 2, 3 and 4, 1.23\% APF gel (Dentonics, Bristol, UK) was applied over the samples by a micro-brush and removed after 4 minutes using cotton rolls.

Er:YAG laser (Smart 2940D plus, Deka, Calenzana, Italy) was irradiated on the samples in groups 3 and 4 with $100 \mathrm{~mJ}$ maximum energy, $1.59 \mathrm{~J} / \mathrm{cm}^{2}$ energy density, $1 \mathrm{~W}$ power, $10 \mathrm{~Hz}$ frequency, $250 \mu$ s pulse width, 10-second duration, $1 \mathrm{~mm}$ spot diameter and 50\% water, using swiping motion at $2 \mathrm{~mm}$ distance from the surface. The irradiated surface area was $16 \mathrm{~mm}^{2}$.

The pH Cycling

All samples were submitted to $\mathrm{pH}$ cycling. For this purpose, the samples of each group were immersed in $200 \mathrm{~mL}$ of Coca-Cola (Khoshgovar Co, Tehran, Iran) containing phosphoric acid with a $\mathrm{pH}$ of 2.4 for 2 minutes, rinsed with deionized water, dried and immersed in artificial saliva (2.91 g NaCL, $0.12 \mathrm{~g} \mathrm{CaCl}_{2}, 0.13 \mathrm{~g} \mathrm{NaH}_{2} \mathrm{PO}_{4}, 5 \mathrm{cc}$ $\mathrm{NaF}, 5 \mathrm{cc} \mathrm{NaN}_{3}$ per $0.5 \mathrm{~L}, \mathrm{pH} \cong 6.5$ ) for 2 hours in an incubator at $37^{\circ} \mathrm{C}$. This process was repeated 4 times a day for 5 days. The $\mathrm{pH}$ of Coca-Cola was measured using a $\mathrm{pH}$ meter. After the last daily erosive process, the samples were stored in the artificial saliva in an incubator during the night. Artificial saliva was renewed daily before the beginning of the erosive process.

Measurement of Final Micro-hardness

The final micro-hardness of the samples was measured by applying $100 \mathrm{~g}$ load for 10 seconds as previously described for the baseline micro-hardness.

\section{Statistical Analysis}

The data were analyzed using SPSS version 22 (SPSS Inc., IL, USA). The normal distribution of the micro-hardness data in each group before and after the erosive process was assessed using the Kolmogorov-Smirnov test. The mean, standard deviation (SD), 95\% confidence interval (95\% $\mathrm{CI}$ ), minimum and maximum micro-hardness values were reported. Two-way ANOVA was utilized to assess the effect of pretreatment in the 4 groups and the type of tooth (permanent/primary) on micro-hardness. The repeated measures ANOVA was applied to compare the baseline and final micro-hardness values in each group. $P<0.05$ was considered statistically significant.

\section{Results}

The mean SMH values of primary and permanent samples at the baseline and after the erosive challenge are described in Tables 1 and 2.

The Kolmogorov-Smirnov test showed that the microhardness data had a normal distribution. Thus, one-way ANOVA was applied and showed no significant difference between primary and permanent enamel samples or the 4 subgroups in terms of baseline micro-hardness.

Repeated measures ANOVA showed that the mean enamel micro-hardness in all subgroups of the permanent and primary teeth after the erosive process decreased compared to baseline micro-hardness and this reduction was statistically significant $(P<0.0001)$.

Comparing the 4 subgroups of the permanent teeth showed that the greatest reduction in the mean $\mathrm{SMH}$ values occurred in the control and $\mathrm{F}$ groups and the least reduction occurred in the FL group, although these differences were not statistically significant $(P>0.05)$.

Comparing the 4 subgroups of the primary teeth showed that the greatest reduction in the mean SMH values occurred in the FL and control groups while the least reduction occurred in the fluoride group. However, these

Table 1. Mean Surface Micro-hardness of the Permanent Teeth Samples at the Baseline, After pH Cycling and Changes in Surface Micro-hardness ( $\Delta$ SMH)

\begin{tabular}{lccr}
\hline \multirow{2}{*}{ Groups } & \multicolumn{2}{c}{ Mean Surface Micro-hardness Values } \\
\cline { 2 - 4 } & Baseline & After pH Cycling & \multicolumn{1}{c}{ MSMH (Baseline -After pH Cycling) } \\
\hline Control & $352.29 \pm 15.51$ & Mean \pm SD & $92.64 \pm 21.20$ \\
F & $349.07 \pm 37.75$ & $259.64 \pm 21.16$ & $92.56 \pm 31.04$ \\
FL & $348.64 \pm 24.05$ & $256.51 \pm 25.26$ & $84.21 \pm 36.80$ \\
LF & $345.68 \pm 28.78$ & $264.42 \pm 31.84$ & $88.45 \pm 48.73$ \\
\hline
\end{tabular}

Table 2. Mean Surface Micro-hardness of the Primary Teeth Samples at the Baseline, After pH Cycling and Changes in Surface Micro-hardness ( $\Delta$ SMH)

\begin{tabular}{lccc}
\hline & \multicolumn{3}{c}{ Mean Surface Micro-hardness Values } \\
\cline { 2 - 4 } Groups & Baseline & After pH Cycling & \multicolumn{1}{c}{ SSMH (Baseline -After pH Cycling) } \\
& Mean \pm SD & Mean \pm SD & $97.50 \pm 57.83$ \\
\hline Control & $340.49 \pm 41.56$ & $242.98 \pm 55.77$ & $87.59 \pm 54.40$ \\
F & $338.49 \pm 32.44$ & $250.90 \pm 55.89$ & $99.73 \pm 21.26$ \\
FL & $351.09 \pm 48.28$ & $251.36 \pm 36.49$ & $91.35 \pm 46.39$ \\
\hline
\end{tabular}


differences were not statistically significant $(P>0.05)$.

The pairwise comparison of the subgroups separately in each of the primary and permanent groups was done using two-way ANOVA. Although no significant difference was noted between the subgroups $(P>0.05)$, in the permanent teeth, change in micro-hardness in FL and LF groups was less than that in the control group. In the primary teeth, change in micro-hardness of the fluoride and LF groups was less than that in the control group.

The pairwise comparison of the primary and permanent enamel subgroups was also performed (Figure 1 ), which showed that the percentage of reduction of micro-hardness in the control, FL and LF subgroups of the permanent teeth was less than that of the primary teeth, but this difference was not statistically significant $(P>0.05)$.

\section{Discussion}

At present, dental erosion is an important factor responsible for the loss of tooth structure in children and adults. ${ }^{3}$ Considering the confirmed efficacy of fluoride in the prevention of tooth decay, ${ }^{38}$ it has also been recommended for the prevention of dental erosion. Many studies have assessed the efficacy of fluoride alone and in combination with other protective measures in the prevention of erosion..$^{3,24,39-42}$ Laser irradiation alone or combined with fluoride application has also been suggested to increase enamel acid resistance, ${ }^{31,43}$ and some studies demonstrated the positive efficacy of Er:YAG laser in increasing enamel resistance against acid attacks and dental caries. ${ }^{30,31,44}$

Although both caries and erosion are caused by the demineralization of enamel, their main etiologic factors and mechanism of development are totally different. Considering the need for further evaluation of the efficacy of Er:YAG laser in the prevention of erosion, this study assessed the effect of Er:YAG laser irradiation combined with fluoride application on primary and permanent enamel resistance to erosion. The results showed that the micro-hardness of both permanent and primary enamel significantly decreased after the erosive process.

Considering the relatively high rate of consumption of carbonated beverages and their significant role in causing dental erosion, ${ }^{1,2}$ Coca-Cola was used in this study as a demineralizing agent. Evidence shows that the consumption of acidic beverages 4 times a day may cause dental erosion, ${ }^{42}$ The low $\mathrm{pH}$ of the oral environment caused by the consumption of these beverages remains for about 2 minutes. ${ }^{45}$ We took these factors into account when simulating frequent acid attacks.

Considering the high absorption of erbium lasers by the tooth structure and its use in the previous studies to minimize enamel demineralization, ${ }^{32,40,44}$ Er:YAG laser was used in this study. To prevent mechanical injury to the enamel, Er:YAG laser with sub-ablative fluency was irradiated on the enamel surfaces.

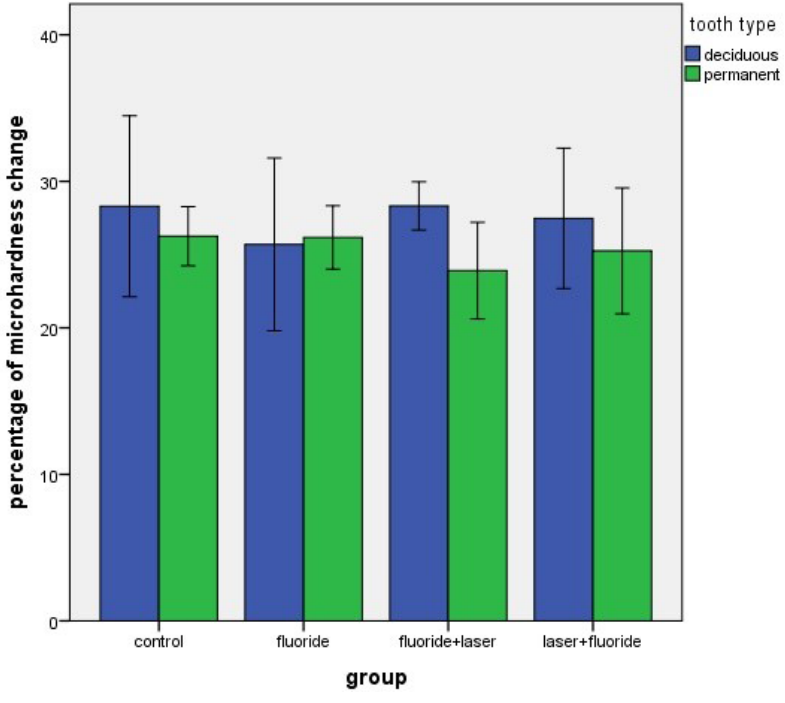

Figure 1. The Percentage of Reduction in Enamel Micro-hardness of The Subgroups of the Primary and Permanent Teeth.

Our results showed that despite the use of different pretreatment measures, enamel micro-hardness of both primary and permanent teeth significantly decreased by the erosive process. In other words, the tested measures could not prevent the erosive effect of Coca-Cola on enamel micro-hardness. This result was in line with that of dos Reis Derceli et al. ${ }^{40}$ They also showed that the Er:YAG laser irradiation, APF gel application or combination of both could not prevent enamel erosion caused by Coca-Cola. Rocha et $\mathrm{al}^{25}$ indicated that the application of stannous fluoride gel alone or combined with $\mathrm{CO}_{2}$ laser irradiation could not protect the primary teeth against the erosive action of hydrochloric acid. However, Azevedo et $\mathrm{al}^{32}$ and Rios et $\mathrm{al}^{22}$ applied Er,YAG laser and $\mathrm{Nd}$ :YAG laser respectively and showed laser irradiation combined with fluoride application minimized enamel loss during erosive processes. Ramalho et $\mathrm{al}^{3,27}$ showed that $\mathrm{AmF} / \mathrm{NaF}$ fluoride gel alone and combined with $\mathrm{CO}_{2}$ laser minimized enamel loss due to exposure to citric acid compared to the control group. The difference between our results and theirs may be due to the use of different types/parameters of lasers or fluoride compounds.

In our study, the reduction in micro-hardness of permanent enamel following pretreatment with fluoride followed by laser irradiation was less than that of the control and fluoride groups. Azevedo et $\mathrm{al}^{32}$ obtained similar results using Er:YAG laser $(80 \mathrm{~mJ}, 2 \mathrm{~Hz})$ and APF gel but with significant differences between the combined groups and the control and fluoride groups. This difference between their findings and ours (in terms of statistical significance) can be due to different laser parameters or the use of water spray during laser irradiation. The absorption of laser energy by water might have decreased the efficacy of combined treatment.

Dos Reis Derceli et $\mathrm{al}^{40}$ reported that the enamel wear (measured by profilometry) during the erosive process 
with Coca-Cola following treatment with Er:YAG laser and APF gel was similar to that in the fluoride group. Although the demineralization of enamel following combined treatment with fluoride followed by the laser was less than that following fluoride application alone, it could not completely stop the erosive enamel wear. However, they did not have a negative control group.

In contrast to our study, Belcheva et $\mathrm{a}^{46}$ and EstevesOliveira et $\mathrm{al}^{28}$ showed that reduction in enamel microhardness following the combined use of $\mathrm{CO}_{2}$ laser and fluoride was significantly smaller than that in the control and APF gel groups. This difference may be due to the use of different laser devices and parameters or the difference in the $\mathrm{pH}$ cycles and the quantitative method for the assessment of erosion.

Our study showed that the reduction in primary enamel micro-hardness in the use of fluoride alone was less than that in the combined treatment groups. Ramos-Oliveira et $\mathrm{al}^{9}$ evaluated permanent molar enamel samples and obtained similar results using $\mathrm{CO}_{2}$ laser. They showed that the protective effect of the laser irradiated before the application of APF gel for the prevention of erosion was less than the efficacy of fluoride application alone.

In the current study, the reduction in enamel microhardness in the FL group was similar to the LF group. Rios et $\mathrm{al}^{22}$ and Azevedo et $\mathrm{al}^{32}$ reported that enamel loss in the FL and LF groups was not significantly different, which is in agreement with the findings of our study.

Controversy exists regarding the susceptibility of primary and permanent teeth to erosion. ${ }^{47}$ Our study showed that the mean micro-hardness in the primary teeth was slightly lower than that of the permanent teeth but not significantly. This was also true for the secondary micro-hardness (after the erosive process). This finding was in line with that of Lussi et $\mathrm{al}^{48}$ and Murakami et $\mathrm{al}^{2}$ showed that the application of APF gel decreased permanent enamel loss during the erosive process with Coca-Cola but it was not effective in the primary teeth. In the control groups, reduction in micro-hardness of the primary teeth was significantly greater than that in the permanent teeth. ${ }^{2}$ These results regarding the permanent teeth are not in accord with our findings. In our study, enamel micro-hardness of the permanent teeth in the fluoride group significantly decreased after the erosive process. Jordao et $\mathrm{al}^{24}$ Sobral et $\mathrm{al}^{21}$ and Scatolin et $\mathrm{al}^{33}$ showed that APF gel decreased the erosive loss of bovine enamel. This controversy in the results may be due to the difference in the study design in terms of the type of tooth, $\mathrm{pH}$ cycling and the quantitative method of erosion assessment. Similar to our study, Azevedo et $\mathrm{al}^{32}$ showed that the application of APF gel alone could not prevent the reduction in enamel micro-hardness during the erosive process.

Further similar studies with a larger sample size are required using profilometry and chemical assessment of the release of calcium and phosphate ions.

\section{Conclusion}

Within the limitations of this study, Er:YAG laser irradiation combined with fluoride application could not prevent erosion in permanent and primary enamel during the erosive process.

\section{Ethical Considerations}

Ethical approval was obtained from the research ethics committee of Shahid Beheshti University (IR.SBMU. RETECH.REC.1396.1120).

\section{Conflict of Interests}

The authors declare no conflict of interest.

\section{Acknowledgements}

This research was supported by the grant of Laser Application in Medical Sciences Research Center of Shahid Beheshti Medical University.

\section{References}

1. Lussi A, Carvalho TS. Erosive tooth wear: a multifactorial condition of growing concern and increasing knowledge. Monogr Oral Sci. 2014;25:1-15. doi: 10.1159/000360380.

2. Murakami C, Bönecker M, Corrêa MSNP, Mendes FM, Rodrigues CRMD. Effect of fluoride varnish and gel on dental erosion in primary and permanent teeth. Arch Oral Biol. 2009;54(11):997-1001. doi: 10.1016/j. archoralbio.2009.08.003.

3. Ramalho KM, Eduardo CP, Heussen N, Rocha RG, Lampert F, Apel C, et al. Protective effect of CO2 laser (10.6 mum) and fluoride on enamel erosion in vitro. Lasers Med Sci. 2013;28(1):71-8. doi: 10.1007/s10103-012-1071-x.

4. Imfeld T. Dental erosion definition, classification and links. Eur J Oral Sci. 1996;104(2):151-55. doi: 10.1111/j.16000722.996.tb00063. x.

5. Zero DT, Lussi A. Erosion-chemical and biological factors of importance to the dental practitioner. Int $J$ Dent. 2005;55(4):285-90. doi: 10.1111/j.1875-595X.2005. tb00066.x.

6. Aranha A, Eduardo CP, Cordás TA. Eating disorders. Part I: Psychiatric diagnosis and dental implications. J Contemp Dent Pract. 2008;9(6):73-81.

7. Aranha A, Eduardo CP, Cordás T. Eating disorders part II: clinical strategies for dental treatment. J Contemp Dent Pract. 2008;9(7):89.

8. Moazzez R, Bartlett D. Intrinsic causes of erosion. Monogr Oral Sci. 2014;25:180-196. doi: 10.1159/000360369.

9. Ramos-Oliveira TM, Ramos TM, Esteves-Oliveira M, Apel $\mathrm{C}$, Fischer $\mathrm{H}$, Eduardo $\mathrm{CP}$, et al. Potential of $\mathrm{CO} 2$ lasers (10.6 microm) associated with fluorides in inhibiting human enamel erosion. Braz Oral Res. 2014;28:1-6. doi: 10.1590/1807-3107BOR-2014.vol28.0057.

10. Passos VF, Melo MA, Silva FF, Rodrigues LK, Santiago SL. Effects of diode laser therapy and stannous fluoride on dentin resistance under different erosive acid attacks. Photomed Laser Surg. 2014;32(3):146-51. doi: 10.1089/ pho.2013.3629.

11. Huysmans MC, Chew HP, Ellwood RP. Clinical studies of dental erosion and erosive wear. Caries Res. 2011;45(1):60- 
8. doi: $10.1159 / 000325947$.

12. Steiner-Oliveira C, Nobre-dos-Santos M, Zero DT, Eckert G, Hara AT. Effect of a pulsed CO2 laser and fluoride on the prevention of enamel and dentine erosion. Arch Oral Biol. 2010;55(2):127-33. doi: 10.1016/j.archoralbio.2009.11.010.

13. Amaechi BT, Higham SM. Dental erosion: possible approaches to prevention and control. J Dent. 2005;33(3):243-52. doi: 10.1016/j.jdent.2004.10.014.

14. Turssi CP, Hara AT, Domiciano SJ, Serra MC. Study on the potential inhibition of root dentine wear adjacent to fluoride-containing restorations. J Mater Sci Mater Med. 2008;19(1):47-51. doi: 10.1007/s10856-007-3140-4.

15. Lussi A. Dental erosion-novel remineralizing agents in prevention or repair. Adv Dent Res. 2009;21(1):13-6. doi: 10.1177/0895937409335592.

16. João-Souza SH, Scaramucci T, Hara AT, Aranha AC. Effect of Nd:YAG laser irradiation and fluoride application in the progression of dentin erosion in vitro. Lasers Med Sci. 2015;30(9):2273-9. doi: 10.1007/s10103-015-1802-x.

17. Saunders JG, McIntyre JM. The ability of $1.23 \%$ acidulated phosphate fluoride gel to inhibit simulated endogenous erosion in tooth roots. Aust Dent J. 2005;50(4):263-6. doi: 10.1111/j.1834-7819.2005.tb00371.x.

18. Ganss C, Schlueter N, Hardt M, Schattenberg P, Klimek J. Effect of fluoride compounds on enamel erosion in vitro: a comparison of amine, sodium and stannous fluoride. Caries Res. 2008;42(1):2-7. doi: 10.1159/000111743.

19. van Rijkom H, Ruben J, Vieira A, Huysmans MC, Truin GJ, Mulder J. Erosion-inhibiting effect of sodium fluoride and titanium tetrafluoride treatment in vitro. Eur J Oral Sci. 2003;111(3):253-7. doi: 10.1034/j.1600-0722.2003.00031.x.

20. Larsen MJ, Richards A. Fluoride is unable to reduce dental erosion from soft drinks. Caries Res. 2002;36(1):75-80. doi: $10.1159 / 000057595$.

21. Sobral MA, Lachowski KM, de Rossi W, Braga SR, Ramalho KM. Effect of Nd:YAG laser and acidulated phosphate fluoride on bovine and human enamel submitted to erosion/abrasion or erosion only: an in vitro preliminary study. Photomed Laser Surg. 2009;27(5):709-13. doi: 10.1089/pho.2008.2318.

22. Rios D, Magalhaes AC, Machado MA, da Silva SM, Lizarelli Rde F, Bagnato VS, et al. In vitro evaluation of enamel erosion after Nd:YAG laser irradiation and fluoride application. Photomed Laser Surg. 2009;27(5):743-7. doi: 10.1089/pho.2008.2384.

23. Scatolin RS, Alonso-Filho FL, Galo R, Rios D, Borsatto $\mathrm{MC}$, Corona SA. $\mathrm{CO}_{2}$ laser emission modes to control enamel erosion. Microsc Res Tech. 2015;78(8):654-9. doi: 10.1002/jemt.22518.

24. Jordão MC, Forti GM, Navarro RS, Freitas PM, Honorio $\mathrm{HM}$, Rios D. $\mathrm{CO}_{2}$ laser and/or fluoride enamel treatment against in situ/ex vivo erosive challenge. J Appl Oral Sci. 2016;24(3):223-8. doi: 10.1590/1678-775720150399.

25. Rocha CT, Turssi CP, Rodrigues-Junior AL, Corona SA. Impact of $\mathrm{CO}_{2}$ laser and stannous fluoride on primary tooth erosion. Lasers Med Sci. 2016;31(3):567-71. doi: 10.1007/s10103-016-1903-1.

26. Lepri TP, Scatolin RS, Colucci V, De Alexandria AK, Maia LC, Turssi CP, et al. In Situ analysis of $\mathrm{CO}_{2}$ laser irradiation on controlling progression of erosive lesions on dental enamel. Microsc Res Tech. 2014;77(8):586-93. doi: 10.1002/ jemt.22377.

27. Ramalho KM, Eduardo CP, Heussen N, Rocha RG, MeyerLueckel H, Lampert F, et al. Randomized in situ study on the efficacy of $\mathrm{CO}_{2}$ laser irradiation in increasing enamel erosion resistance. Clin Oral Investig.2019;23(5):2103-12. doi: 10.1007/s00784-018-2648-y.

28. Esteves-Oliveira M, Pasaporti C, Heussen N, Eduardo CP, Lampert F, Apel C. Rehardening of acid-softened enamel and prevention of enamel softening through $\mathrm{CO}_{2}$ laser irradiation. J Dent. 2011;39(6):414-21. doi: 10.1016/j. jdent.2011.03.006.

29. Freitas PM, Simoes A. Lasers in dentistry guide for clinical practice. Wiley-Blackwell; 2015. p. 74.

30. Castellan CS, Luiz AC, Bezinelli LM, Lopes RM, Mendes $\mathrm{FM}$, Eduardo $\mathrm{CP}$, et al. In vitro evaluation of enamel demineralization after Er:YAG and Nd:YAG laser irradiation on primary teeth. Photomed Laser Surg. 2007;25(2):85-90. doi: 10.1089/pho.2006.2043.

31. Correa-Afonso AM, Ciconne-Nogueira JC, Pecora JD, Palma-Dibb RG. Influence of the irradiation distance and the use of cooling to increase enamel-acid resistance with Er:YAG laser. J Dent. 2010;38(7):534-40. doi: 10.1016/j. jdent.2010.03.009.

32. Azevedo DT, Faraoni-Romano JJ, dos Reis Derceli J, Palma-Dibb RG. Er: YAG laser effect on bovine enamel microhardness after erosive challenge. Revista Odonto Ciência. 2012;27(4):329-32.

33. Scatolin RS, Colucci V, Lepri TP, Maia LC, Galo R, Borsatto MC, et al. Er: YAG laser irradiation to control the progression of enamel erosion: an in situ study. Lasers Med Sci. 2015;30(5):1465-73. doi: 10.1007/s10103-014-1620-6.

34. Scatolin RS, Colucci V, Lepri TP, Alexandria AK, Maia LC, Galo R, et al. Non-contact profilometry of eroded and abraded enamel irradiated with an Er:YAG laser. $J$ Appl Oral Sci. 2018;26. doi: 10.1590/1678-7757-2017-0029.

35. Kwon YH, Lee JS, Choi YH, Lee JM, Song KB. Change of enamel after Er:YAG and CO2 laser irradiation and fluoride treatment. Photomed Laser Surg. 2005;23(4):38994. doi: 10.1089/pho.2005.23.389.

36. Delbem AC, Cury JA, Nakassima CK, Gouveia VG, Theodoro LH. Effect of Er:YAG laser on $\mathrm{CaF}_{2}$ formation and its anti-cariogenic action on human enamel: an in vitro study.J Clin Laser Med Surg. 2003;21(4):197-201. doi: $10.1089 / 104454703768247765$.

37. Chuenarrom C, Benjakul P, Daosodsai P. Effect of indentation load and time on knoop and vickers microhardness tests for enamel and dentin. Mat Res. 2009;12(4):473-6. doi: 10.1590/S1516-14392009000400016.

38. Ten Cate JM. Review on fluoride, with special emphasis on calcium fluoride mechanisms in caries prevention. Eur J Oral Sci. 1997;105:461-5. doi: 10.1111/j.1600-0722.1997. tb00231.x.

39. Magalhães AC, Wiegand A, Rios D, Honório HM, Buzalaf MAR. Insights into preventive measures for dental erosion. J Appl Oral Sci. 2009;17(2):75-86. doi: 10.1590/S167877572009000200002.

40. dos Reis Derceli J, Faraoni-Romano JJ, Azevedo DT, Wang L, Bataglion C, Palma-Dibb RG. Effect of pretreatment with an Er:YAG laser and fluoride on the prevention of 
dental enamel erosion. Lasers Med Sci. 2015;30(2):857-62. doi: 10.1007/s10103-013-1463-6.

41. Pereira L, Joao-Souza SH, Bezerra S, Borges AB, Aranha A, Scaramucci T. Nd:YAG laser irradiation associated with fluoridated gels containing photo absorbers in the prevention of enamel erosion. Lasers Med Sci. 2017;32(7):1453-59. doi: 10.1007/s10103-017-2226-6.

42. Lussi A, Carvalho TS. The future of fluorides and other protective agents in erosion prevention. Caries Res. 2015;49(1):18-29. doi: 10.1159/000380886.

43. Moslemi M, Fekrazad R, Tadayon N, Ghorbani M, Torabzadeh H, Shadkar MM. Effects of Er;Cr:YSGG laser irradiation and fluoride treatment on acid resistance of the enamel. Pediatr Dent. 2009;31(5):409-13.

44. Liu Y, Hsu CY, Teo CM, Teoh SH. Subablative Er:YAG laser effect on enamel demineralization. Caries Res.
2013;47(1):63-8. doi: 10.1159/000343573.

45. Young A, Tenua LM. Initial erosion models. Caries Res. 2011;45(1):33-42. doi: 10.1159/000325943.

46. Belcheva A, El Feghali R, Nihtianova T, Parker S. Effect of the carbon dioxide 10,600-nm laser and topical fluoride gel application on enamel microstructure and microhardness after acid challenge: an in vitro study. Lasers Med Sci. 2018;33(5):1009-17. doi: 10.1007/s10103-018-2446-4.

47. Hara AT, Lussi A, Zero DT. Biological factors. Monogr Oral Sci. 2006;20:88-99. doi: 10.1159/000093355.

48. Lussi A, Kohler N, Zero D, Schaffner M, Megert B. A comparison of the erosive potential of different beverages in primary and permanent teeth using an in vitro model. Eur J Oral Sci. 2000;108(2):110-4. doi: 10.1034/j.16000722.2000.90741.x 